\title{
Impact of cholinesterase inhibitors or memantine on survival in adults with Down syndrome and dementia: clinical cohort study
}

Nicole Eady*, Rory Sheehan*, Khadija Rantell, Amanda Sinai, Jane Bernal, Ingrid Bohnen, Simon Bonell, Ken Courtenay, Karen Dodd, Dina Gazizova, Angela Hassiotis, Richard Hillier, Judith McBrien, Kamalika Mukherji, Asim Naeem, Natalia Perez-Achiaga, Vijaya Sharma, David Thomas, Zuzana Walker, Jane McCarthy† and André Strydom†

\section{Background}

There is little evidence to guide pharmacological treatment in adults with Down syndrome and Alzheimer's disease.

\section{Aims}

To investigate the effect of cholinesterase inhibitors or memantine on survival and function in adults with Down syndrome and Alzheimer's disease.

\section{Method}

This was a naturalistic longitudinal follow-up of a clinical cohort of 310 people with Down syndrome diagnosed with Alzheimer's disease collected from specialist community services in England.

\section{Results}

Median survival time (5.59 years, 95\% Cl 4.67-6.67) for those on medication ( $n=145$, mainly cholinesterase inhibitors) was significantly greater than for those not prescribed medication $(n=165)$ (3.45 years, 95\% $\mathrm{Cl} 2.91-4.13$, log-rank test $P<0.001)$. Sequential assessments demonstrated an early effect in maintaining cognitive function.

\section{Conclusions}

Cholinesterase inhibitors appear to offer benefit for people with Down syndrome and Alzheimer's disease that is comparable with sporadic Alzheimer's disease; a trial to test the effect of earlier treatment (prodromal Alzheimer's disease) in Down syndrome may be indicated

\section{Declaration of interest}

A.S. has undertaken consulting for Ono Pharmaceuticals, outside the submitted work. Z.W. has received a consultancy fee and grant from GE Healthcare, outside the submitted work.

\section{Copyright and usage}

(c) The Royal College of Psychiatrists 2018.
The life expectancy of people with Down syndrome has increased greatly over the past several decades and many people with the condition now live into older age. ${ }^{1,2}$ People with Down syndrome have a higher risk of developing Alzheimer's disease than the general population. ${ }^{3}$ There is good evidence that cholinesterase inhibitors (donepezil, rivastigmine or galantamine) and memantine, a non-competitive $N$-methyl-D-aspartate receptor antagonist, can improve cognitive function and behaviour in people with Alzheimer's disease who do not have intellectual disabilities; ${ }^{4,5}$ however, people with Down syndrome have been excluded from most trials of antidementia drugs and the evidence that they are effective in this group remains inconclusive. ${ }^{6-9}$

The aim of this study was to determine the effect of cholinesterase inhibitors or memantine on survival and cognitive and adaptive function in a large clinical cohort of people with Down syndrome and Alzheimer's disease.

\section{Method}

\section{Data source}

Data were obtained from the Aging with Down Syndrome and Intellectual Disability (ADSID) database, a research database conceived following the regular meetings of a regional dementia in intellectual disability special interest group. ${ }^{10}$ The ADSID database contains the clinical information of over 1000 adults with intellectual disability who have been assessed in specialist memory clinics for adults with intellectual disability. Data were collected by the authors from the clinical records held by psychiatry of intellectual

* These authors contributed equally to this work.

† These authors are joint last authors. disability community teams across London and the south of England. Demographic and clinical details were extracted from the patient notes, pseudonymised at source and added to the database, which is held securely at University College London.

Data include, degree and aetiology of intellectual disability, physical and psychiatric comorbidities (with a particular emphasis on those that are common in people with Down syndrome and those that are related to cognitive functioning such as thyroid disorder, past or current history of depression, epilepsy and sensory impairment) and psychotropic drug prescription. Dates of clinical assessments and the results of standardised cognitive tests are also recorded. Many of those included have been under regular clinic follow-up and have contribute data from several sequential assessments. Date and cause of death is recorded, where applicable. The database contains information from clinical assessments conducted between 2000 and 2013, when the research database was superseded.

\section{Ethics}

Ethical approval for use of the ADSID database in research studies was obtained from the Newcastle and North Tyneside 1 Research Ethics Committee (reference 10/H0906/30). Special permission was received from the National Information Governance Board for Health and Social Care Ethics and Confidentiality Committee to process patient identifiable information at source without consent (reference ECC 5-04(h)/2010). The Caldicott Guardian of organisations providing information authorised data collection and transfer of pseudonymised data.

\section{Study participants}

We included all people in the ADSID database with Down syndrome and a diagnosis of Alzheimer's disease made after January 
2000. Data collection finished in 2013. A record of Down syndrome in the individual's clinical notes or results of genetic tests indicating Down syndrome was taken as evidence of the condition. The diagnosis of dementia was made by the person's own clinical team and the assessment process was determined by local protocols, as there is no agreed standard for dementia assessment in Down syndrome. In line with current best practice guidance, diagnostic assessments were expected to have been undertaken by an experienced clinician and to include medical history, neuropsychiatric assessment, and physical and mental state examination, and exclusion of other causes of decline. ${ }^{11}$ If there was uncertainty about the diagnosis of Down syndrome or Alzheimer's disease the participant was excluded from the study. We collected a minimum data-set for each participant and excluded those for whom insufficient data were available.

The cohort was divided into groups based on prescription of medication for dementia, first into those who had been prescribed medication and those who had not, then by medication class and drug prescribed. A separate category was created for individuals who had been prescribed both cholinesterase inhibitors and memantine. The dates of starting, stopping and switching medication were recorded, where available. Where the date of starting medication was not known, the date of dementia diagnosis was considered the most likely date of prescription and used as a proxy.

\section{Outcomes and measures}

The Dementia Questionnaire for People with Learning Disabilities (DLD) was used to measure baseline and changes in cognitive and adaptive function. ${ }^{12}$ The DLD is a routinely-used standardised informant-based questionnaire consisting of 50 items grouped into eight categories that the informant is asked to rate on a linear scale based on observations made over the preceding 6 months. Completing the DLD yields two subscores; a sum of cognitive scores (SCS, covering memory and orientation); a sum of social scores (SSS, covering aspects of behaviour and adaptive function). Higher scores indicate more severe impairment. The DLD is a sensitive tool in tracking changes over time in people with Down syndrome and cognitive decline, and is recommended as a tool to supplement clinical assessment in people with intellectual disability in the National Institute for Health and Care Excellence dementia pathway. ${ }^{13-15}$

Baseline score was defined as the DLD at the point of diagnosis (or the last recorded DLD prior to diagnosis), first assessment and second assessment DLD scores were the first and second subsequent clinical assessments after a diagnosis of dementia, which occurred at variable times after diagnosis based on local clinical policies and individual need. Clinicians were also asked to rate patients as having early-, middle- or late-stage dementia based on the overall clinical picture and their clinical judgement.

Where available, the latest recorded DLD score prior to (or at) dementia diagnosis and the DLD scores at first and second followup appointments after the diagnosis were compared between those prescribed and not prescribed acetylcholinesterase inhibitors or memantine.

\section{Statistical analysis}

Numerical data were summarised using mean, standard deviation or median and range depending on data distribution. Categorical data were summarised using count and percentages. We carried out simple analyses using the independent $t$-test or MannWhitney $U$-test, and the chi-squared test to compare the groups defined by dementia medication status. We used multivariable linear regression to assess the difference in DLD score between the groups, adjusting for pre-treatment values. ${ }^{16}$
The primary outcome measure was death. Survival time was defined as the time in years between the date of diagnosis of Alzheimer's disease and the date of death. Participants were censored if they were alive or dead with no known date of death. We used the Kaplan-Meier method to estimate the median survival times. Survival time was defined as the time between dementia diagnosis and last assessment or date of death. Participants who were alive were censored at the date of the last clinic assessment. Participants who died were censored at the date of death. We censored the small number of participants who had died but for whom date of death was missing, at the date of the last clinic assessment. We used log-rank tests to evaluate the survival distributions of different groups (antidementia medication status and medication class). ${ }^{17}$

We examined the effect of the following pre-defined set of potential confounding variables on survival: age at dementia diagnosis; gender; degree of intellectual disability; antipsychotic use; past history of depression (recorded diagnosis or prescription of antidepressant medication); current or past history of thyroid disease (recorded diagnosis or prescription of thyroid-specific medication); history of epilepsy preceding dementia diagnosis; and vision or hearing impairment.

Factors associated with death were analysed with Cox's proportional hazard model. ${ }^{18}$ We used $20 \%$ as the threshold for statistical significance in the univariable analysis to identify the variables that indicate a reasonable degree of association with the outcome and that were then added to the multivariable model. ${ }^{19}$ We also used the backward elimination selection procedure with a $20 \%$ significance level to verify the stability of the variable selection process. ${ }^{20}$ The final multivariable model included site, age at dementia diagnosis, gender and degree of intellectual disability. We tested the validity of the proportional hazard assumption by plotting log-minus-log survival curves and carrying out Schoenfeld tests. ${ }^{18}$

Statistical analyses were performed using Stata, version 13. No formal sample size calculation was carried out. It is recommended that at least ten events per estimated parameter are required in order to avoid the problem of overfitting, which can arise if the model contains fewer events compared with the number of variables in the Cox regression model. ${ }^{18}$ Missing data were not imputed.

\section{Results}

Data were collected from 18 psychiatry of intellectual disability clinical teams across four broad geographical regions. A total of 310 individuals with Down syndrome and dementia were included (174 male, 56.1\%). Approximately a third (35.2\%) of the cohort had mild-moderate intellectual disability (IQ range 35-69), a third $(33.2 \%)$ had severe-profound intellectual disability (IQ $<35$ ), and the degree of intellectual disability was not recorded for the remainder (31.6\%).

\section{Descriptive characteristics of study participants}

In total, 145 (47\%) of the study participants were prescribed antidementia medication and 165 (53\%) were not prescribed such medication (Table 1). Those prescribed antidementia medication were younger at diagnosis $(53.8 v .56 .6$ years, $P=0.0003)$ and a greater proportion had mild-moderate intellectual disability $(P<0.0001)$.

Total DLD score, SCS and the SSS at diagnosis, were significantly higher in the group not prescribed medication, indicating that this group had more severe symptoms of dementia at diagnosis. A greater proportion of those prescribed antidementia drugs were assessed as having early dementia by clinicians, and a greater 
Table 1 Comparison of baseline demographic and clinical characteristics by antidementia medication status of the study participants $(n=$ 310)

\begin{tabular}{|c|c|c|c|}
\hline & \multicolumn{2}{|c|}{ Prescribed medication } & \multirow[b]{2}{*}{$P^{a}$} \\
\hline & $\begin{array}{l}\text { No } \\
(n=165)\end{array}$ & $\begin{array}{l}\text { Yes } \\
(n=145)\end{array}$ & \\
\hline Follow-up, years: mean (s.d.) & $5.61(4.97)$ & $4.79(4.49)$ & 0.0639 \\
\hline Age at diagnosis $(n=310)$, mean (s.d.) & $56.55(6.40)$ & $53.81(6.63)$ & 0.0003 \\
\hline $\begin{array}{l}\text { Gender }(n=310), n(\%) \\
\quad \text { Male }(n=174) \\
\text { Female }(n=136)\end{array}$ & $\begin{array}{l}88(51) \\
77(57)\end{array}$ & $\begin{array}{l}86(49) \\
59(43)\end{array}$ & 0.290 \\
\hline $\begin{array}{l}\text { Intellectual disability }(n=212), n(\%) \\
\text { Mild }(n=51) \\
\text { Moderate }(n=58) \\
\text { Severe }- \text { profound }(n=103)\end{array}$ & $\begin{array}{r}6(12) \\
19(33) \\
57(55) \\
\end{array}$ & $\begin{array}{l}45(88) \\
39(67) \\
46(45)\end{array}$ & $<0.0001$ \\
\hline $\begin{array}{l}\text { Region }(n=310), n(\%) \\
\text { Region A }(n=66) \\
\text { Region B }(n=85) \\
\text { Region C }(n=32) \\
\text { Region D }(n=127)\end{array}$ & $\begin{aligned} 32 & (48) \\
6 & (7) \\
8 & (25) \\
117(92) & \end{aligned}$ & $\begin{array}{l}34(52) \\
79(93) \\
24(75) \\
10(8)\end{array}$ & $<0.0001$ \\
\hline $\begin{array}{l}\text { Thyroid disease }(n=175), n(\%) \\
\text { Yes }(n=86) \\
\text { No }(n=89)\end{array}$ & $\begin{array}{l}51(59) \\
64(72)\end{array}$ & $\begin{array}{l}35(41) \\
25(28)\end{array}$ & 0.079 \\
\hline $\begin{array}{l}\text { Epilepsy }(n=262), n(\%) \\
\text { Yes }(n=52) \\
\text { No }(n=210)\end{array}$ & $\begin{array}{r}31(60) \\
103(49) \\
\end{array}$ & $\begin{array}{r}21(40) \\
107(51) \\
\end{array}$ & 0.172 \\
\hline $\begin{array}{l}\text { Sensory impairment }(n=176), n(\%) \\
\text { Yes }(n=122) \\
\text { No }(n=54)\end{array}$ & $\begin{array}{l}85(70) \\
36(67)\end{array}$ & $\begin{array}{l}37(30) \\
18(33)\end{array}$ & 0.692 \\
\hline $\begin{array}{l}\text { Depression }(n=162), n(\%) \\
\text { Yes }(n=27) \\
\text { No }(n=135)\end{array}$ & $\begin{array}{l}17(63) \\
87(64)\end{array}$ & $\begin{array}{l}10(37) \\
48(36)\end{array}$ & 0.883 \\
\hline $\begin{array}{l}\text { Dementia severity at diagnosis } \\
\qquad(n=52), n(\%) \\
\text { Early }(n=38) \\
\text { Middle }(n=13) \\
\text { Late }(n=1)\end{array}$ & $\begin{aligned} 18 & (47) \\
9 & (69) \\
1 & (100)\end{aligned}$ & $\begin{aligned} 20 & (53) \\
4 & (31) \\
0 & (0)\end{aligned}$ & 0.255 \\
\hline $\begin{array}{l}\text { DLD score at diagnosis, mean (s.d.) } \\
\text { Sum of cognitive scores }(n=136) \\
\text { Sum of social scores }(n=133) \\
\text { Total }(n=139)\end{array}$ & $\begin{array}{l}30.54(9.60) \\
28.32(13.17) \\
55.92(21.46)\end{array}$ & $\begin{array}{l}25.35(11.00) \\
20.84(10.60) \\
45.04(20.30)\end{array}$ & $\begin{array}{l}0.0247 \\
0.0126 \\
0.0266\end{array}$ \\
\hline $\begin{array}{l}\text { a. P-values obtained from: two-sample indep } \\
\text { chi-squared tests as appropriate for the scale } \\
\text { bold are significant. }\end{array}$ & $\begin{array}{l}\text { endent } t \text {-test, } \\
\text { and distributi }\end{array}$ & $\begin{array}{l}\text { ann-Whitney U-te } \\
\text { of the variable. R }\end{array}$ & $\begin{array}{l}\text {-test, and } \\
\text { Results in }\end{array}$ \\
\hline
\end{tabular}

proportion in the non-prescribed group had middle or late dementia, although the differences in these proportions were not statistically significant.

There was no significant difference in gender or rates of measured comorbidities between those prescribed and not prescribed antidementia medication.

\section{Impact of acetylcholinesterase inhibitors or memantine on survival}

The Kaplan-Meier survival curves following diagnosis of dementia for those prescribed and not prescribed antidementia drugs show a significant difference in survival time between those prescribed and not prescribed antidementia medication (Fig. 1(a)). Median survival time on any antidementia drug was 5.59 years (95\% CI $4.67-6.67$ ) whereas median survival time of those not prescribed any antidementia drug was 3.45 years (95\% CI 2.91-4.13; log-rank test $P<0.0001)$. Prescription of cholinesterase inhibitors, either alone or in combination with memantine, conferred a survival advantage; median survival time for those prescribed an acetylcholinesterase inhibitor was 6.15 years (95\% CI 4.44-?.??). (The upper confidence limit in this case was not calculable from the data. The median

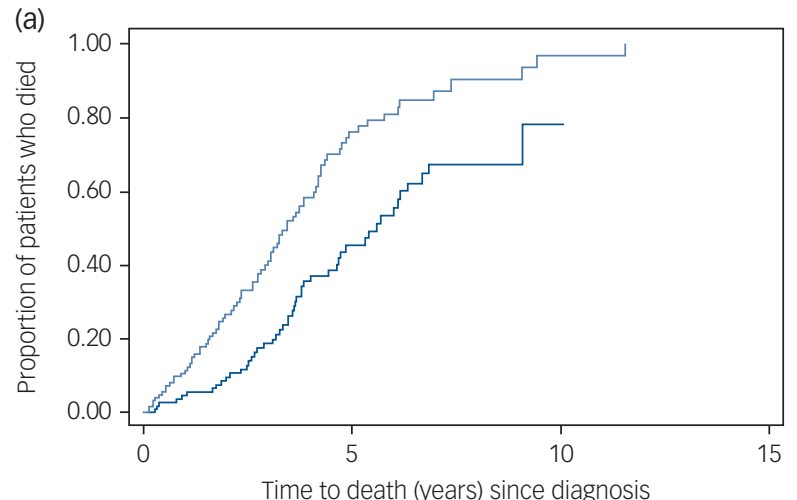

Number at risk

On drug 124

Not on drug 127

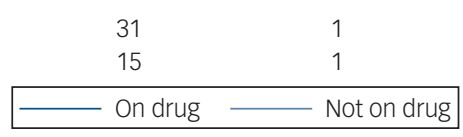

(b)

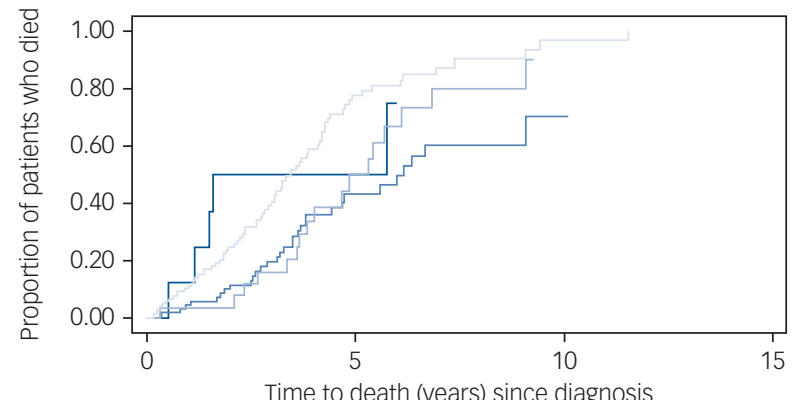

Number at risk

Memantine 8

AChE-inhibitor 99

Both 25

Neither 119

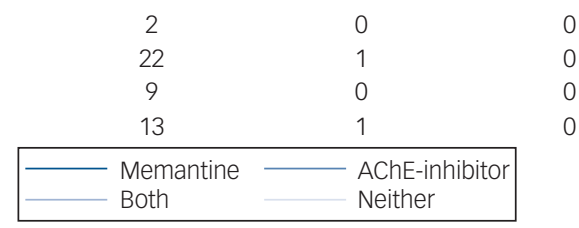

Fig. 1 Difference in survival time: (a) between those prescribed

and not prescribed anti-dementia medication and (b) by anti-

dementia drug type or no medication.

AChE-inhibitor, acetylcholinesterase inhibitor.

survival time represents the time beyond which $50 \%$ of subjects are expected to survive. Confidence intervals for the median survival time are not based on standard errors but are obtained by inverting the respective 100 (1-alpha)\% confidence interval for the survivor function. A missing upper confidence limit in this case indicates that this limit could not be determined. For these groups the estimated upper confidence limit of the survivor function never falls below $0.5 .^{38}$ ) The median survival time of those people prescribed both memantine and an acetylcholinesterase inhibitor was 5.31 years (95\% CI 3.65-6.10) (Fig. 1(b)). In contrast, median survival time on no medication was 3.45 years $(95 \%$ CI $2.91-4.13$, logrank test $P=0.0001$ ).

Factors that conferred a higher hazard of death during the observation period were, increased age at diagnosis, more severe intellectual disability and having pre-existing epilepsy (supplementary Table 1; available at http://doi.org/10.1192/bjp.2017.21). These were entered into a multivariable Cox regression (with region and gender as fixed factors) to investigate the effect of different variables on survival after a diagnosis of dementia (Table 2).

Those who were prescribed antidementia medication had a lower risk of death than those who were not prescribed antidementia medication, but this association was not statistically significant 
Table 2 Adjusted and unadjusted hazard ratio (HR) for death, derived from a Cox regression model

\begin{tabular}{|c|c|c|c|c|}
\hline & \multicolumn{2}{|c|}{ Unadjusted analysis } & \multicolumn{2}{|c|}{ Adjusted analysis $^{\mathrm{a}}$} \\
\hline & $\mathrm{HR}(95 \% \mathrm{Cl})$ & $P$ & $\mathrm{HR}(95 \% \mathrm{Cl})$ & $P$ \\
\hline \multicolumn{5}{|l|}{ On medication $(n=255)$} \\
\hline Yes & $0.46(0.33-0.66)$ & $<0.0001$ & $0.65(0.32-1.32)$ & 0.235 \\
\hline No & Reference & & & \\
\hline Medication class $(n=303)$ & & 0.0002 & & 0.0788 \\
\hline Memantine alone $(n=8)$ & $1.02(0.41-2.53)$ & & $2.05(0.62-6.78)$ & \\
\hline AChE-inhibitor alone $(n=105)$ & $0.41(0.27-0.62)$ & & $0.59(0.28-1.23)$ & \\
\hline Both $(n=26)$ & $0.57(0.33-0.97)$ & & $0.81(0.32-2.09)$ & \\
\hline Neither $(n=164)$ & Reference & & & \\
\hline Type of medication $(n=251)$ & & 0.0001 & & 0.165 \\
\hline Donepezil $(n=31)$ & $0.22(0.09-0.54)$ & & $0.50(0.17-1.50)$ & \\
\hline Rivastigmine $(n=41)$ & $0.71(0.42-1.19)$ & & $0.58(0.25-1.35)$ & \\
\hline Galantamine $(n=51)$ & $0.44(0.27-0.70)$ & & $0.55(0.23-1.31)$ & \\
\hline Combination of drug $(n=9)^{b}$ & $0.26(0.10-0.73)$ & & $0.26(0.08-0.85)$ & \\
\hline Neither $(n=171)$ & Reference & & Reference & \\
\hline
\end{tabular}

after accounting for confounding variables (adjusted hazard ratio $0.65,95 \%$ CI $0.32-1.32, P=0.235$ ). There were no statistically significant differences between different classes of antidementia medication, although prescription of cholinesterase inhibitors (either alone or in combination with memantine) was consistently associated with a lower hazard ratio of death than prescription of memantine alone. There was no difference in hazard ratio of death between the different cholinesterase inhibitors. We conducted a sensitivity analysis where the regression model did not include level of intellectual disability as this variable included a high degree of missing data; in this analysis (including 254 people) the adjusted hazard ratio of death for those prescribed antidementia medication was 0.45 (95\% CI 0.25-0.82, $P=0.009)$.

\section{DLD score}

The median time between the baseline and first assessment after diagnosis was 191 days (6.1 months, interquartile range (IQR) $=139-303$ days) and between first and second assessments was 183 days (5.9 months, IQR=166-233 days). The cognitive score (SCS) was significantly lower in the group that received medication at first follow-up assessment (indicating better cognitive functioning); this advantage was lost by the time of the second follow-up appointment. The sum of social scores (SSS, indicating functional abilities) showed no differences between the groups (Table 3).

\begin{tabular}{|c|c|c|c|}
\hline DLD & Coefficient $^{a}$ & $95 \% \mathrm{Cl}$ & $P$ \\
\hline \multicolumn{4}{|l|}{ Cognition score (SCS) } \\
\hline Baseline $(n=125)$ & -0.074 & -2.87 to 2.72 & 0.958 \\
\hline First assessment $(n=110)$ & -4.37 & -8.53 to -0.21 & 0.040 \\
\hline Second assessment $(n=95)$ & 0.24 & -4.76 to 5.25 & 0.923 \\
\hline \multicolumn{4}{|l|}{ Social score (SSS) } \\
\hline Baseline $(n=124)$ & -1.34 & -4.90 to 2.22 & 0.458 \\
\hline First assessment $(n=102)$ & -2.70 & -7.78 to 2.39 & 0.295 \\
\hline Second assessment $(n=92)$ & -0.05 & -4.70 to 4.60 & 0.983 \\
\hline \multicolumn{4}{|c|}{$\begin{array}{l}\text { SCS, sum of cognitive scores; SSS, sum of social scores. } \\
\text { Result in bold is significant. } \\
\text { a. Regression coefficient adjusted for pre-treatment score. The coefficient represents } \\
\text { the mean difference (on medication - not on medication). }\end{array}$} \\
\hline
\end{tabular}


intellectual disability, and the prevalence of prescribing is likely to have changed over the time period that our data were derived. The results suggest that care pathways should be standardised for this group to ensure equitable treatment, given some evidence of early benefit at the cognitive level.

\section{Comparison with existing literature}

The effect of antidementia drugs on survival in people without Down syndrome is uncertain; some studies report increased survival in people prescribed antidementia drugs, ${ }^{21,22}$ yet other studies do not. $^{23,24} \mathrm{~A}$ underlying mechanism by which antidementia medications might reduce mortality has not been established but it has been hypothesised that the effect is mediated by protective effects of the drugs on atherosclerotic cardiovascular risk. ${ }^{25}$ However, the relevance of such a mechanism to people with Down syndrome might be offset by the relatively low observed rates of atherosclerotic disease in this group. ${ }^{26}$

Our results accord with a number of existing small studies that have explored the symptomatic benefit of cholinesterase inhibitors for people with Down syndrome and Alzheimer's disease and shown potential for limited benefit of these drugs. ${ }^{27-31}$ The benefit of cholinesterase inhibitors has been reported to occur within the first 3-6 months of treatment, ${ }^{27,32}$ consistent with our own results. Our findings are also in keeping with recent evidence from clinical studies of cholinesterase inhibitors in adults with sporadic Alzheimer's disease, also showing a larger response during the first 6 months of treatment, ${ }^{33}$ and donepezil treatment decreased the annual rate of hippocampal atrophy in a recent randomised controlled trial in prodromal Alzheimer's disease. ${ }^{34}$ Better cognitive functioning could permit people to attend to and better manage their physical health, thus improving survival.

\section{Strengths and limitations of the study}

This study adds to the limited evidence base on the effectiveness of antidementia medication in people with Down syndrome and Alzheimer's disease. It is the first study to provide outcome data comparing different classes of antidementia drugs, and on the use of galantamine in this population. Data were collected over several years from a range of real-world clinical services covering urban and rural locations. The people included have a range of concomitant health issues as might be expected in a population of ageing adults with Down syndrome and are likely to be representative of those who are known to specialist community services nationally.

The widespread acceptance and use of cholinesterase inhibitors and memantine in people with Down syndrome and Alzheimer's disease in contemporary clinical care ${ }^{35}$ makes it difficult to justify a controlled drug trial where some participants do not receive these drugs and the observational design of our study is therefore appropriate in this context. Our results suggest significant cognitive benefit during the initial 6 months of treatment of cholinesterase inhibitors in individuals with Down syndrome who have been diagnosed with Alzheimer's disease, which requires further exploration.

There are certain limitations to this observational study. It is not possible to determine a causal relationship between prescription of cholinesterase inhibitors and survival. There were significant baseline differences between the groups prescribed and not prescribed antidementia medication. Those who were not prescribed medication were older, more likely to have severe-profound intellectual disability, and had more severe dementia symptoms at baseline. Although we adjusted for major measured confounders in the analysis, because of lack of randomisation the results might be subject to residual confounding and influenced by unknown or unmeasured variables that could account for some of the differences associated with medication treatment we have observed.

There are difficulties in recognising and diagnosing dementia in people with Down syndrome who have pre-existing cognitive impairment. It is possible that a small number of people may have been misdiagnosed; however, we have shown in a previous study that clinical diagnoses of dementia made in these specialist teams are valid and reliable. ${ }^{10}$

Owing to this being a study using routine clinical data, there were missing data and variation in time points of assessment that limited our analyses and the strength of the conclusions that we are able to draw. We did not have data on the dose of medication or adherence with treatment. The low numbers of people prescribed memantine prevent us from drawing strong inferences based on the obtained results; however, our results are in keeping with a randomised controlled trial that has shown that this drug is not effective for Alzheimer's disease in Down syndrome. ${ }^{9}$

Further work is needed to investigate the effect of all antidementia drugs on a broader set of cognitive and functional outcomes, including longer-term outcomes such as time to admission to higher care settings.

\section{Implications}

While we await advances in the understanding of the pathophysiology of Alzheimer's disease relevant to people with Down syndrome that might permit interventions to delay the onset or even prevent $i{ }^{3}{ }^{3}$ identifying optimum treatment for those living with the disease must be a priority. Notwithstanding the limitations of this study, the results of this work lend support to the prescription of cholinesterase inhibitors as first-line pharmacological intervention for people with Down syndrome and Alzheimer's disease and suggest that they might increase survival and reduce the rate of cognitive decline in the early stages after diagnosis. Although people with Down syndrome are likely to have comorbid health conditions as they age, cholinesterase inhibitors are relatively safe in this population, ${ }^{27,36}$ and anecdotal evidence suggests that adverse side-effects should not be a barrier to prescription if supplemented by regular monitoring.

Alzheimer's disease is a major concern for people with Down syndrome who are increasingly living into older age. Dementia has wide-ranging implications for the person affected, their family and paid carers, and the system of medical and social supports that are likely to be required as the disease progresses. ${ }^{37}$ Early diagnosis and improved care pathways are likely to have a positive impact on the provision of other aspects of care. A clinical trial of treatment with cholinesterase inhibitors during the early symptomatic stages of cognitive decline in Down syndrome before a formal dementia diagnosis should be considered to test whether early response can be maximised, and to determine if cognitive benefit is related to functional improvement and is of cost-benefit.

Nicole Eady, MRCPsych, Division of Psychiatry, University College London, London; Rory Sheehan, MRCPsych, Division of Psychiatry, University College London, London; Khadija Rantell, PhD, Education Unit, Institute of Neurology, London; Amanda Sinai, MD, Division of Psychiatry, University College London, London; Jane Bernal, MRCPsych, Cornwall Partnership Foundation Trust, Cornwall; Ingrid Bohnen, MRCPsych, Westminster Learning Disability Partnership, London; Simon Bonell, MRCPsych, Plymouth Community Learning Disabilities Team, Livewell Southwest, Plymouth; Ken Courtenay, FRCPsych, Haringey Learning Disability Partnership, Barnet Enfield Haringey Mental Health NHS Trust, London; Karen Dodd, PhD, Surrey and Borders Partnership NHS Foundation Trust, Leatherhead; Dina Gazizova, MRCPsych, Hillingdon Learning Disabilities Service, Uxbridge, London; Angela Hassiotis, FRCPSych, PhD, Division of Psychiatry, University College London, London; Richard Hillier, PhD, Islington Learning Disabilities Partnership, London; Judith McBrien, D Clin Psych, Plymouth Teaching Primary Care Trust, Plymouth; Kamalika Mukherji, MRCPsych, Hertfordshire Partnership NHS Foundation Trust, Stevenage; Asim Naeem, MRCPsych, South West 
London and St George's Mental Health NHS Trust, London; Natalia Perez-Achiaga MRCPsych, Royal Borough of Kensington and Chelsea Learning Disability Service, London; Vijaya Sharma, MRCPsych, Hertfordshire Partnership NHS Foundation Trust, Stevenage; David Thomas, MRCPsych, Hackney Learning Disability Team, East London NHS Foundation Trust, London; Zuzana Walker, FRCPsych, MD, Division of Psychiatry, University College London, London; Jane McCarthy, FRCPsych, MD, Institute of Psychiatry, Psychology and Neuroscience, King's College London, London; André Strydom, MRCPsych, PhD, Division of Psychiatry, University College London, London; Institute of Psychiatry, Psychology and Neuroscience, King's College London, London, UK; The LonDowns Consortium.

Correspondence: Rory Sheehan, Division of Psychiatry, University College London, 6th Floor Maple House, 149 Tottenham Court Road, London W1T 7NF. Email: r.sheehan@ucl. ac.uk

First received 18 Aug 2017, final revision 27 Oct 2017, accepted 7 Nov 2017

\section{Supplementary material}

Supplementary material is available online at http://doi.org/10.1192/ bjp.2017.21.

\section{Funding}

The Baily Thomas Charitable Fund.

\section{Acknowledgements}

The authors wish to thank the clinicians and services that submitted data to the ADSID database.

\section{References}

1 Yang Q, Rasmussen SA, Friedman J. Mortality associated with Down's syndrome in the USA from 1983 to 1997: a population-based study. Lancet 2002; 359: 1019-25.

2 Englund A, Jonsson B, Zander CS, Gustafsson J, Annerén G. Changes in mortality and causes of death in the Swedish Down syndrome population. Am J Med Genet A 2013; 161: 642-9.

3 Wiseman FK, Al-Janabi T, Hardy J, Karmiloff-Smith A, Nizetic D, Tybulewicz VL, et al. A genetic cause of Alzheimer disease: mechanistic insights from Down syndrome. Nat Rev Neurosci 2015; 16: 564-74.

4 Birks JS. Cholinesterase inhibitors for Alzheimer's disease. Cochrane Database Syst Rev 2006; 1: CD005593.

5 McShane R, Areosa Sastre A, Minakaran N. Memantine for dementia. Cochrane Database Syst Rev 2006; 2: CD003154.

6 Mohan M, Bennett C, Carpenter PK. Galantamine for dementia in people with Down syndrome. Cochrane Database Syst Rev 2009; 1: CD007656.

7 Mohan M, Bennett C, Carpenter PK. Rivastigmine for dementia in people with Down syndrome. Cochrane Database Syst Rev 2009; 1: CD007658.

8 Mohan M, Carpenter PK, Bennett C. Donepezil for dementia in people with Down syndrome. Cochrane Database Syst Rev 2009; 1: CD007178.

9 Hanney M, Prasher V, Williams N, Jones EL, Aarsland D, Corbett A, et al. Memantine for dementia in adults older than 40 years with Down's syndrome (MEADOWS): a randomised, double-blind, placebo-controlled trial. Lancet 2012; 379: 528-36.

10 Sheehan R, Sinai A, Bass N, Blatchford P, Bohnen I, Bonell S, et al. Dementia diagnostic criteria in Down syndrome. Int J Geriatr Psychiatry 2015; 30: 857-63.

11 Royal College of Psychiatrists and the British Psychological Society. Dementia and People with Intellectual Disabilities. The British Psychological Society, 2015.

12 Eurlings HAL, Evenhuis HM, Kengen MMF. Dementia Questionnaire for People with Learning Disabilities (DLD). UK adaptation. Harcourt Assessment, 2006.

13 Evenhuis $\mathrm{H}$. Evaluation of a screening instrument for dementia in ageing mentally retarded persons. J Intell Disabil Res 1992; 36: 337-47.

14 Prasher V. Dementia questionnaire for persons with mental retardation (DMR): modified criteria for adults with Down's syndrome. J Appl Res Intellect 1997; 10: $54-60$.
15 McCarron M, McCallion P, Reilly E, Mulryan N. A prospective 14-year longitudinal follow-up of dementia in persons with Down syndrome. J Intell Disabil Res 2014; 58: 61-70.

16 Altman D. Practical Statistics for Medical Research. Chapman and Hall, 1991.

17 Lee ET. Nonparametric methods of estimating survival functions. In Statistical Methods for Survival Data Analysis (3rd edn) (eds ET Lee and J Wang): 64-105. John Wiley \& Sons, 2003.

18 Harrell F. Regression Modeling Strategies: with Applications to Linear Models, Logistic and Ordinal Regression, and Survival Analysis. Springer, 2015.

19 Mickey R, Greenland S. A study of the impact of confounder-selection criteria on effect estimation. Am J Epidemiol 1989; 129: 125-37.

20 Ambler G, Seaman S, Omar R. An evaluation of penalised survival methods for developing prognostic models with rare events. Stat Med 2012; 31: 1150-61.

21 Wu C-Y, Hu H-Y, Chow L-H, Chou YJ, Huang N, Wang PN, et al. The effects of anti-dementia and nootropic treatments on the mortality of patients with dementia: a population-based cohort study in Taiwan. PloS One 2015; 10 e0130993.

22 Zhu CW, Livote EE, Scarmeas N, Albert M, Brandt J, Blacker D, et al. Long-term associations between cholinesterase inhibitors and memantine use and health outcomes among patients with Alzheimer's disease. Alzheimers Dement 2013; 9: $733-40$.

23 Suh G-H, Ryu S-H, Lee D-W, Han C, Ju YS, Kee BS, et al. Cholinesterase inhibitors for Alzheimer disease: do they provide more than symptomatic benefits? Am Geriatr Psychiatry 2011; 19: 266-73.

24 Rountree SD, Chan W, Pavlik VN, Darby EJ, Doody RS. Factors that influence survival in a probable Alzheimer disease cohort. Alzheimers Res Ther 2012; 4: 16.

25 Nordström P, Religa D, Wimo A, Winblad B, Eriksdotter M. The use of cholinesterase inhibitors and the risk of myocardial infarction and death: a nationwide cohort study in subjects with Alzheimer's disease. Eur Heart J 2013; 34: 2585-91.

26 Vis J, Duffels M, Winter M, Weijerman ME, Cobben JM, Huisman SA, et al. Down syndrome: a cardiovascular perspective. J Intell Disabil Res 2009; 53: 419-25.

27 Lott IT, Osann K, Doran E, Nelson L. Down syndrome and Alzheimer disease: response to donepezil. Arch Neurol 2002; 59: 1133-6.

28 Prasher V, Fung $\mathrm{N}$, Adams $\mathrm{C}$. Rivastigmine in the treatment of dementia in Alzheimer's disease in adults with Down syndrome. Int J Geriatr Psychiatry 2005; 20: 496-7.

29 Prasher V, Huxley A, Haque M. A 24-week, double-blind, placebo-controlled trial of donepezil in patients with Down syndrome and Alzheimer's diseasepilot study. Int J Geriatr Psychiatry 2002; 17: 270-8.

30 Prasher V, Sachdeva N, Adams C, Haque M. Rivastigmine transdermal patches in the treatment of dementia in Alzheimer's disease in adults with Down syndrome-pilot study. Int J Geriatr Psychiatry 2013; 28: 219-20.

31 Atri A, Hendrix SB, Pejović V, Hofbauer RK, Edwards J, Molinuevo JL, et al. Cumulative, additive benefits of memantine-donepezil combination over component monotherapies in moderate to severe Alzheimer's dementia: a pooled area under the curve analysis. Alzheimers Res Ther 2015; 7: 28

32 Kishnani PS, Sullivan JA, Walter BK, Spiridigliozzi GA, Doraiswamy PM, Krishnan KRR. Cholinergic therapy for Down's syndrome. Lancet 1999; 353 . 1064-5.

33 Perera $\mathrm{G}$, Khondoker $\mathrm{M}$, Broadbent $\mathrm{M}$, Breen $\mathrm{G}$, Stewart $\mathrm{R}$. Factors associated with response to acetylcholinesterase inhibition in dementia: a cohort study from a secondary mental health care case register in London. PloS One 2014; 9 : e109484.

34 Dubois B, Chupin M, Hampel H, Lista S, Cavedo E, Croisile B, et al. Donepezil decreases annual rate of hippocampal atrophy in suspected prodromal Alzheimer's disease. Alzheimers Dement 2015; 11: 1041-9.

35 National Institute for Health and Care Excellence. Dementia: Supporting People with Dementia and their Carers in Health and Social Care. CG42. National Institute for Health and Care Excellence, 2006

36 Kishnani PS, Spiridigliozzi GA, Heller JH, Sullivan JA, Doraiswamy PM, Krishnan KRR. Donepezil for Down's syndrome. Am J Psychiatry 2001; 158: 143.

37 Janicki MP, Dalton AJ. Prevalence of dementia and impact on intellectual disability services. Ment Retard 2000; 38: 276-88

38 Cleves, et al. An Introduction to Survival Analysis Using Stata, Revised Third Edition. College Station, Texas: Stata Press, 2016 